\title{
Evaluation of Fetal Clavicular Length as a Sonological Parameter for the Estimation of Gestational Age
}

\author{
Dr. Debasish Dey ${ }^{1}$, Dr. Sandip Kumar Ghosh ${ }^{2 *}$, Dr. SK Wasim Raja ${ }^{3}$, Dr. Krishnendu Dolui ${ }^{4}$, Dr. Anup Kumar Bairagi ${ }^{5}$
}

\author{
${ }^{1}$ Assistant Professor, Department of Radio-diagnosis, R.G. Kar Medical College, Kolkata-4, India \\ ${ }^{2}$ Associate Professor, Department of Radio-diagnosis, Bankura Sammilani Medical College \& Hospital, Bankura, India \\ ${ }^{3}$ Consultant Radiologist, West Bengal, India \\ ${ }^{4} 2^{\text {nd }}$ year PGT, Department of Radio-diagnosis, Bankura Sammilani Medical College \& Hospital, Bankura, India \\ ${ }^{5} 3^{\text {rd }}$ year PGT, Department of Radio-diagnosis, Bankura Sammilani Medical College \& Hospital, Bankura, India
}

DOI: $10.36347 /$ sjams.2021.v09i03.005

| Received: 14.02.2021| Accepted: 25.02.2021| Published: 04.03.2021

*Corresponding author: Dr. Sandip Kumar Ghosh

\section{Abstract}

Original Research Article

Background: Presently the most effective way to date the pregnancy is by the use of ultrasound. Several sonologically derived fetal parameters used to date pregnancy includes biparietal diameter (BPD), head circumference (HC), abdominal circumference (AC) and femur length (FL). However the variability in assessing gestational age with these parameters goes on increasing as the pregnancy advances. The present study was undertaken to evaluate the usefulness of clavicular length (CL) as against other conventional parameters in normal pregnancies. Aims: To describe the relationships between sonologically assessed fetal clavicular length and gestational age in all pregnant women between 17 to 36 weeks. To create a nomogram between the same. Materials and methods: A cross sectional descriptive study was conducted in the department of radio-diagnosis, Bankura Sammilani Medical College \& Hospital with time frame of 18 (eighteen) months from February, 2018 to July, 2019). Gestational age and fetal calvicular length was determined using Ultrasound machine PHILIPS HD7 (2.0.1) with 3-5 MHz curvilinear transducer. Data was compiled in Microsoft (MS) excel sheet and then analysed by appropriate statistical methods. Statistical software package like Software packages for social sciences (spss version 20) was utilised. Results: It was found that there is significant correlation $(\mathrm{P}<0.001)$ between fetal clavicular length (in $\mathrm{mm})$ and fetal

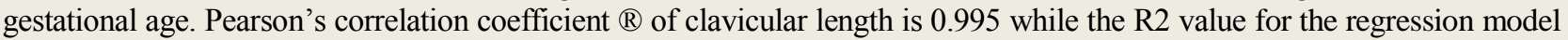
is 0.990. Conclusions: There is statistically significant correlation between Fetal Clavicular Length (CL) and other parameters in normal pregnancies at 17 to 36 week of gestation. Clavicular length (CL) is better parameter for gestational age compared to BPD, HC and AC as seen by the R2 values of the individual regression models conducted in this study. The nomograms and quadratic equation derived from the measured CL data can be used to predict the gestational age of fetus.

Keywords: Correlation, regression coefficient, fetal clavicular length, gestational age.

Copyright (C) 2021 The Author(s): This is an open-access article distributed under the terms of the Creative Commons Attribution 4.0 International License (CC BY-NC 4.0) which permits unrestricted use, distribution, and reproduction in any medium for non-commercial use provided the original author and source are credited.

\section{INTRODUCTION}

The commonest problem an obstetrician faces frequently is the assessment of fetal maturity for either prolonging the pregnancy or terminating it for complications such as fetal distress, pregnancy induced hypertension, diabetes and $\mathrm{Rh}$ incompatibility diseases. The means that are widely accepted for determination of fetal maturity are Gestational age and Weight of the fetus. The methods used to estimate gestational age (GA) and predict the expected date of delivery are Menstrual History, Clinical Examination, Perception of fetal movement, The Naegele's Rule Expected date of delivery calculation based on last menstrual period has its own set of limitations like vague menstrual history, pregnancy during lactational amenorrhea, first trimester bleeding per vagina and irregular menstrual cycle, leading to false calculations [1]. Menstrual history could be misleading for a number of reasons, such as. Many women do not accurately recall the first day of the last menstrual period, particularly if they are not trying to conceive. LMP may be unreliable or misleading because of oligomenorrhea, abnormal bleeding events, use of oral contraceptive pills and becoming pregnant in the first ovulatory cycle after a recent delivery. Ovulating very early (<day 11 ) or very late (>day 21) in the menstrual cycle. The most common indication for obstetric sonogram is related to uncertainty regarding the gestational age and presently the most effective way to date pregnancy is by the use of ultrasound. Estimation of an accurate gestational age is 
pivot and pillar for management of pregnancies especially high risk cases. Most of the ultrasound based screening tests, biochemical tests, serological tests are being carried at a specific gestational age, during pregnancy. Accurate measurement of gestational age of fetus, major congenital anomalies, fetal well-being and maturity all have become possible due to the availability of ultrasound [2, 3]. Ultrasonography helps in evaluating the duration of pregnancy based on measurement of fetus, using size as an indirect indicator of menstrual age. Among the various biometric indices for fetal gestational age estimation, most commonly used is Hadlock based composite gestational age assessment from biparietal diameter (BPD), head circumference (HC), abdominal circumference (AC), and femur length (FL) [4-6]. A major advantage of fetal biometry using ultrasonography is the prenatal diagnosis of various congenital anomalies [7]. However the above mentioned Hadlock based biometric indices shows variable results in cases of engaged head, macrosomia and congenital anomalies and variability in assessing the gestational age with these parameters goes on increasing with increasing gestational age [8-13].. Ultrasonographic measurements of many fetal osseous structures have been widely used in the last two decades in order to determine gestational age (GA), and to evaluate fetal growth and development [14-16]. Recently nomograms for other osseous structures, such as the clavicle, foot length, mandible, sacrum, scapula, vertebral arch and iliac bone have been established and suggested for use in the evaluation of GA and fetal growth. Measurement of the clavicle is of special interest since it permits not only the estimation of gestational age, but also the detection of severe congenital anomalies such as Cleidocranial dysplasia, Holt-Oram syndrome, Melnick-Needles syndrome and others [17-24]. Measurement of the clavicle by ultrasonography is easily obtainable. The aim of the present study is to predict GA as an adjunct for cases with positional problems that make measurement of some parameters such as FL, difficult and/or fetus with abnormal cranial shape or a deeply engaged fetal head in which proper measurement of BPD can often be difficult. This cross sectional descriptive study has been conducted emphasising on evaluating easily measurable clavicular length as a parameter for gestational age determination, taking subjects from both second and third trimesters into account. Two primary ossification center of clavicle appear on 5-6 weeks of gestation and fuse together about one week later [25], which makes it easy to visualize on ultrasound. With this background the present study was undertaken to determine the correlation between fetal clavicular length and gestational age.

\section{Materials ANd Methods}

A cross sectional descriptive study was conducted in the department of radio-diagnostic B.S.M.C. \& H. with time frame of 18 (eighteen) months from February, 2018 to July, 2019). 200 willing pregnant women in 2nd and 3rd trimester between the ages of 18 to 35 years were taken arbitrarily. Study was approved by institutional ethics committee and consent was obtained from all study participants. Gestational from 17 to 36 were included in the study. After completion of the PNDT formalities ultrasound was performed on Philips (Model no of the Ultrasonography Machine is HD7- 2.0.1) machine using a $3.5 \mathrm{MHz}$ curvilinear transducer. The fetus was first observed for viability and gross anatomical defects, thereafter average gestational age was estimated using Hadlock's formula from established fetal biometric indices like abdominal circumference (AC), head circumference (HC), Femur length (FL), biparietal diameter (BPD) and at the same time fetal clavicular length was measured on axial section from medial end to the lateral end of clavicle as end points. Lengths were measured by fixing electronic calipers at the two end points of clavicle on the axial section. Three measurements were taken in millimeters and its average was recorded in data sheet for data analysis.

\section{EXCLUSION CRITERIA}

a) Mothers with irregular menstrual cycle

b) Oligohydramnios or Polyhydramnios

c) Multiple pregnancies

d) Gross maternal obesity

e) Gestational diabetes mellitus or other endocrinopathies

\section{f) Pre-eclamsia}

g) Maternal cardiac anomalies

h) Mothers not giving consent

i) Mothers on ovulation induction drugs

Data was compiled in Microsoft (MS) excel sheet and then analysed by appropriate statistical methods. Pearson's correlation coefficient and regression coefficient was used to establish relationship between input and outcome variables e.g. between gestational age and Clavicular length as well as between gestational age and other fetal biometric indices. Significance level is at $\mathrm{p}$ value $<0.05$ at two tails. Statistical software package like Software packages for social sciences (spss version 20) was utilised.

\section{RESULTS}

Clavicular length gives a reliable cstimate of fetal gestational age. We calculated Pearson's correlation between gestational ages determined by hadlock formula with the fetal clavicular length (Table 2 ). There was appositive correlation between mean clavicular length \& gestational age determined from hadlocks based BPD, FL, AC \& HC $(p<0.001)$. The relationship between gestational age and mean fetal clavicular length is positively correlated with Pearson's correlation coefficient value of 0.995 and a significance of $(\mathrm{p}<0.001)$ as shown in Table 2. Table-2 also illustrates an exteremely strong correlation with other variables as well like with AC ( $\mathrm{r}=0.992), \mathrm{HC}(\mathrm{r}=0.994)$, $\operatorname{BPD}(r=0.992), F L(r=0.996)$. Scatter plots were drawn between gestational age (independent variable) and clavicular length (dependent variable) to depict the best 
Debasish Dey et al; Sch J App Med Sci, Mar, 2021; 9(3): 322-328

fit line, linear regression equation, its slope and intercept (fig 4). We can seen from the graph of figure 1 that a statistically significant linear relationship was established between clavicular length and gestational age. The regression equation being. Gestational age $=$ $2.110+1.001 *$ clavicular length. Where, $2.110=\mathrm{Y}$ intercept, $1.001=$ Slope, Pearsons correlation Coefficient $(r)=0.995$.

\section{Figures AND TABLeS}

Table-1: Distribution of participants according to fetal clavicular length and duration of gestational age

\begin{tabular}{|c|c|c|l|c|c|c|}
\hline GA(Wks) & Mean(mm) & SD & Median & Range & Minimum & Maximum \\
\hline 17 & 15.92 & 0.35 & 16.0 & 1.1 & 15.3 & 16.4 \\
\hline 18 & 16.43 & 0.33 & 16.4 & 1.1 & 15.9 & 17.0 \\
\hline 19 & 17.83 & 0.45 & 17.9 & 1.4 & 17.1 & 18.5 \\
\hline 20 & 18.34 & 0.42 & 18.3 & 1.3 & 17.9 & 19.2 \\
\hline 21 & 19.05 & 0.54 & 19.0 & 1.9 & 18.3 & 20.2 \\
\hline 22 & 20.16 & 0.39 & 20.2 & 1.3 & 19.3 & 20.6 \\
\hline 23 & 20.94 & 0.55 & 20.9 & 1.8 & 19.9 & 21.7 \\
\hline 24 & 22.48 & 0.68 & 22.1 & 1.9 & 21.6 & 23.5 \\
\hline 25 & 23.27 & 0.32 & 23.3 & 1.9 & 22.8 & 23.7 \\
\hline 26 & 23.97 & 0.34 & 24.0 & 1.2 & 23.1 & 24.3 \\
\hline 27 & 25.16 & 0.62 & 25.3 & 2.0 & 24.1 & 26.1 \\
\hline 28 & 26.12 & 0.41 & 26.1 & 1.2 & 25.6 & 26.8 \\
\hline 29 & 27.44 & 0.35 & 27.4 & 1.0 & 27.0 & 28.0 \\
\hline 30 & 28.34 & 0.46 & 28.3 & 1.7 & 27.4 & 29.1 \\
\hline 31 & 29.35 & 0.86 & 29.6 & 2.2 & 27.9 & 30.8 \\
\hline 32 & 30.63 & 0.41 & 30.6 & 1.1 & 30.1 & 31.2 \\
\hline 33 & 31.16 & 0.42 & 31.1 & 1.4 & 30.5 & 31.9 \\
\hline 34 & 32.51 & 0.50 & 32.6 & 1.7 & 31.4 & 33.1 \\
\hline 35 & 33.49 & 0.36 & 33.6 & 1.2 & 32.8 & 34.0 \\
\hline 36 & 34.34 & 0.39 & 34.4 & 1.1 & 33.8 & 34.9 \\
\hline
\end{tabular}

Table-2: Results of correlation analysis between individual parameters and gestational age Correlations

\begin{tabular}{|c|c|c|c|c|c|c|c|}
\hline \multicolumn{3}{|l|}{ FL } & BPD & $\mathrm{HC}$ & $\mathrm{AC}$ & GA & $\mathrm{CL}$ \\
\hline \multirow[t]{3}{*}{ FL } & Pearson Correlation & 1 & $.995^{* *}$ & $.996^{* *}$ & $.996^{* *}$ & $.996^{* *}$ & $.991^{* *}$ \\
\hline & Sig. (2-tailed) & & $<.001$ & $<.001$ & $<.001$ & $<.001$ & $<.001$ \\
\hline & $\mathrm{N}$ & 200 & 200 & 200 & 200 & 200 & 200 \\
\hline \multirow{3}{*}{$\begin{array}{l}\text { BP } \\
\text { D }\end{array}$} & Pearson Correlation & $.995^{* *}$ & 1 & $.997^{* *}$ & $.993^{* *}$ & $.992^{* *}$ & $.986^{* *}$ \\
\hline & Sig. (2-tailed) & $<.001$ & & $<.001$ & $<.001$ & $<.001$ & $<.001$ \\
\hline & $\mathrm{N}$ & 200 & 200 & 200 & 200 & 200 & 200 \\
\hline \multirow[t]{3}{*}{$\mathrm{HC}$} & Pearson Correlation & $.996^{* *}$ & $.997^{* *}$ & 1 & $.995^{* *}$ & $.994^{* *}$ & $.989^{* *}$ \\
\hline & Sig. (2-tailed) & $<.001$ & $<.001$ & & $<.001$ & $<.001$ & $<.001$ \\
\hline & $\mathrm{N}$ & 200 & 200 & 200 & 200 & 200 & 200 \\
\hline \multirow[t]{3}{*}{$\mathrm{AC}$} & Pearson Correlation & $.996^{* *}$ & $.993^{* *}$ & $.995^{* *}$ & 1 & $.992^{* *}$ & $.994^{* *}$ \\
\hline & Sig. (2-tailed) & $<.001$ & $<.001$ & $<.001$ & & $<.001$ & $<.001$ \\
\hline & $\mathrm{N}$ & 200 & 200 & 200 & 200 & 200 & 200 \\
\hline \multirow[t]{3}{*}{ GA } & Pearson Correlation & $.996^{* *}$ & $.992^{* *}$ & $.994^{* *}$ & $.997^{* *}$ & 1 & $.996^{* *}$ \\
\hline & Sig. (2-tailed) & $<.001$ & $<.001$ & $<.001$ & $<.001$ & & $<.001$ \\
\hline & $\mathrm{N}$ & 200 & 200 & 200 & 200 & 200 & 200 \\
\hline \multirow[t]{3}{*}{ CL } & Pearson Correlation & $.991^{* *}$ & $.986^{* *}$ & $.989^{* *}$ & $.994^{* *}$ & $.995^{* *}$ & 1 \\
\hline & Sig. (2-tailed) & $<.001$ & $<.001$ & $<.001$ & $<.001$ & $<.001$ & \\
\hline & $\mathrm{N}$ & 200 & 200 & 200 & 200 & 200 & 200 \\
\hline
\end{tabular}

**. Correlation is significant at the 0.01 level (2-tailed). 
Debasish Dey et al; Sch J App Med Sci, Mar, 2021; 9(3): 322-328

Table-3: Comparison of intercept and regression coefficient of linear equation of clavicular length with gestational age between present and past studies

\begin{tabular}{|l|l|c|c|c|}
\hline STUDY & $\begin{array}{c}\text { LINEAR REGRESSION } \\
\text { EQUATION }\end{array}$ & $\begin{array}{c}\text { REGRESSION } \\
\text { COEFFIENT }\end{array}$ & P VALUE & $\mathbf{R}^{\mathbf{2}}$ \\
\hline Present Study & $\mathrm{Y}=2.110+1.001 * \mathrm{X}$ & 0.995 & $<0.001$ & 0.990 \\
\hline Shaul Yarkoni et. al. $[26]$ & $\mathrm{Y}=3.717+0.827 * \mathrm{X}$ & 0.816 & $<0.001$ & 0.807 \\
\hline Fazil Avci et al. $[27]$ & $\mathrm{Y}=2.49+0.93 * \mathrm{X}$ & 0.965 & $<0.001$ & 0.930 \\
\hline Sherer DM et al. ${ }^{28]}$ & $\mathrm{Y}=-0.41+0.83 * \mathrm{X}$ & 0.973 & $<0.001$ & 0.960 \\
\hline
\end{tabular}

Table-4: Regression analysis between fetal clavicular length and average fetal gestational age (Table 3A to 3C) Table-3A

Model Summary ${ }^{\text {b }}$

\begin{tabular}{|c|c|c|c|c|c|c|c|c|c|}
\hline \multirow{2}{*}{\multicolumn{2}{|c|}{ Model R }} & \multirow[b]{2}{*}{ R Square } & \multirow{2}{*}{$\begin{array}{l}\text { Adjusted } \\
\text { R Square }\end{array}$} & \multirow{2}{*}{$\begin{array}{c}\text { Std. Error } \\
\text { of the } \\
\text { Estimate }\end{array}$} & \multicolumn{5}{|c|}{ Change Statistics } \\
\hline & & & & & R Square & F Change & df1 & df2 & Sig. F \\
\hline 1 & $0.995^{\mathrm{a}}$ & 0.990 & 0.990 & 0.48624 & 0.990 & 28049.092 & 1 & 198 & 0.000 \\
\hline
\end{tabular}

a. Predictors: (Constant), CL

b. Dependent Variable: GA

Table-3B: ANOVA ${ }^{\text {a }}$

\begin{tabular}{|l|l|l|r|l|l|l|}
\hline \multicolumn{2}{|l|}{ Sum of Model Squares } & \multicolumn{1}{c|}{ df } & Mean Square & \multicolumn{1}{c|}{ F } & Sig. \\
\hline \multicolumn{1}{|l|}{ Regression } & 6631.666 & 1 & 6631.666 & 28049.092 & $.000 \mathrm{~b}$ \\
\hline \multirow{2}{*}{} & Residual & 46.813 & 198 & .236 & & \\
\cline { 2 - 7 } & Total & 6678.480 & 199 & & & \\
\hline
\end{tabular}

a. Dependent Variable: GA

b. Predictors: (Constant), CL

Table-3C

\begin{tabular}{|l|c|c|c|c|c|c|c|}
\hline \multirow{3}{*}{ Model } & \multicolumn{2}{|c|}{$\begin{array}{c}\text { Unstandardized } \\
\text { Coefficients }\end{array}$} & $\begin{array}{c}\text { Standardized } \\
\text { Coefficients }\end{array}$ & \multirow{2}{*}{$\mathbf{t}$} & \multirow{2}{*}{ Sig. } & \multicolumn{2}{|c|}{$\begin{array}{c}\text { 95.0\% Confidence } \\
\text { Interval for B }\end{array}$} \\
\cline { 2 - 4 } \cline { 5 - 7 } & $\mathbf{B}$ & $\begin{array}{c}\text { Std. } \\
\text { Error }\end{array}$ & Beta & & & $\begin{array}{c}\text { Lower } \\
\text { Bound }\end{array}$ & $\begin{array}{c}\text { Upper } \\
\text { Bound }\end{array}$ \\
\hline \multirow{2}{*}{ (Constant) CL } & 2.110 & 0.154 & & 13.695 & .000 & 1.807 & 2.415 \\
\cline { 2 - 8 } & 1.001 & 0.006 & 0.995 & 167.479 & .000 & .989 & 1.012 \\
\hline
\end{tabular}

From above tables linear regression equation for this study obtained is $y(G A)=1.001 \times C L+2.110[y=m x+c]$ and plotted on graph paper.

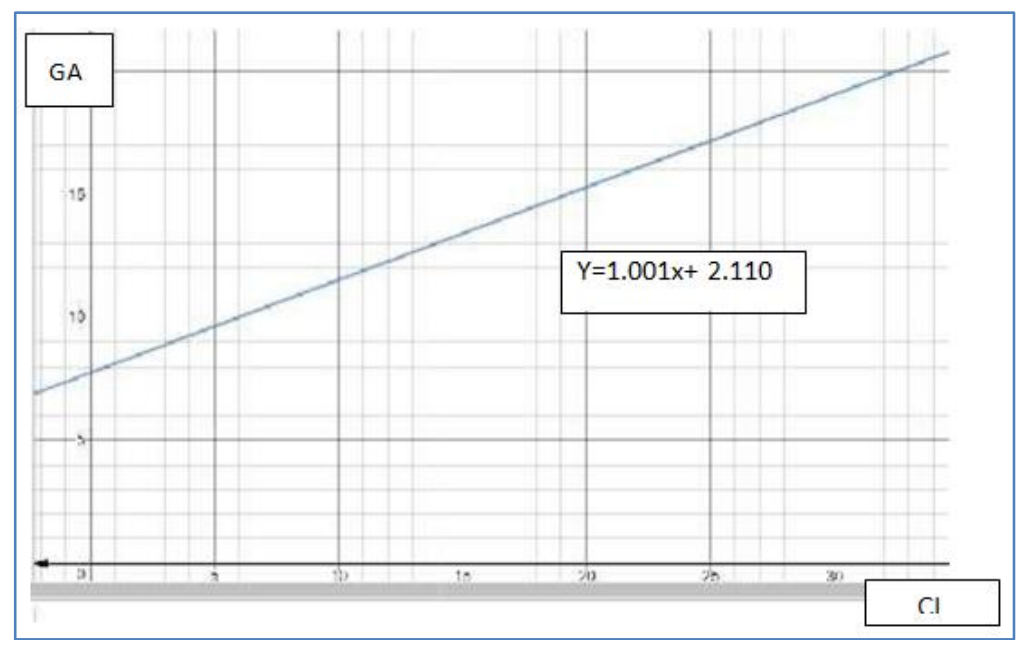

Fig-1: Linear regression equation of CL \& GA 


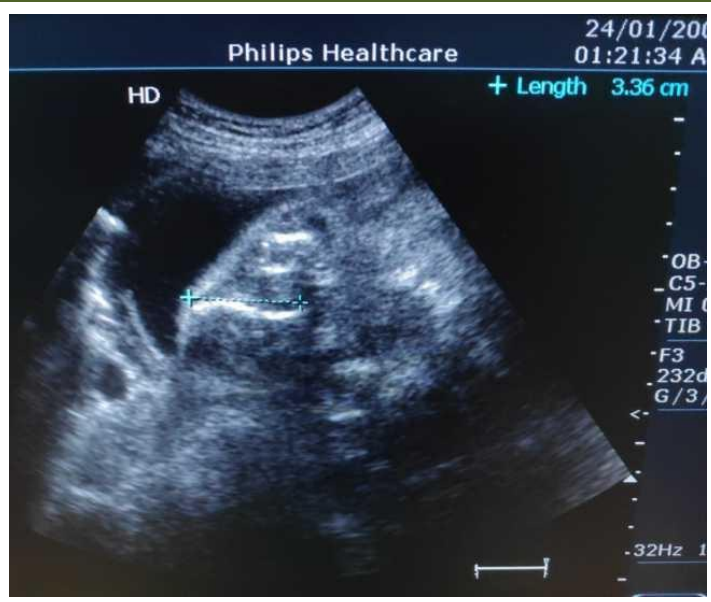

Fig-2: Ultrasonographic measurement of Clavicular Length as seen using curvilinear transducer

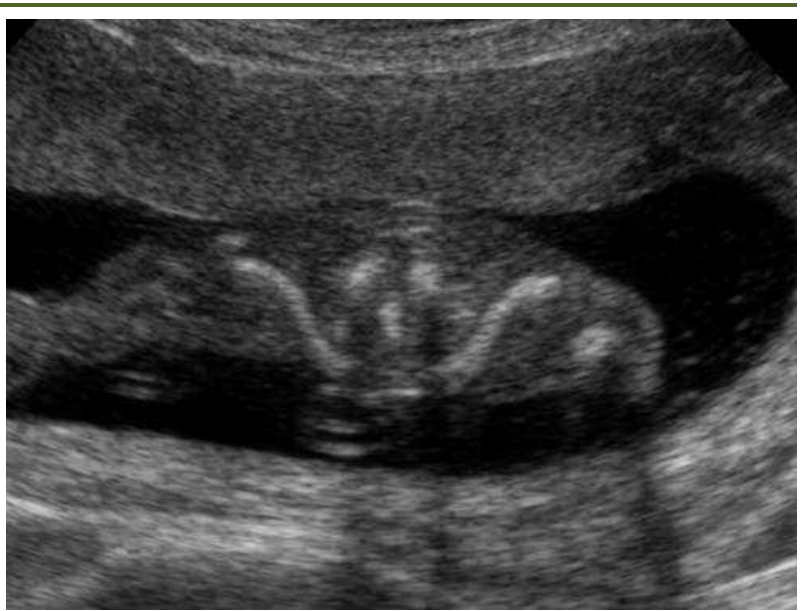

Fig-3: Bilateral Clavicles

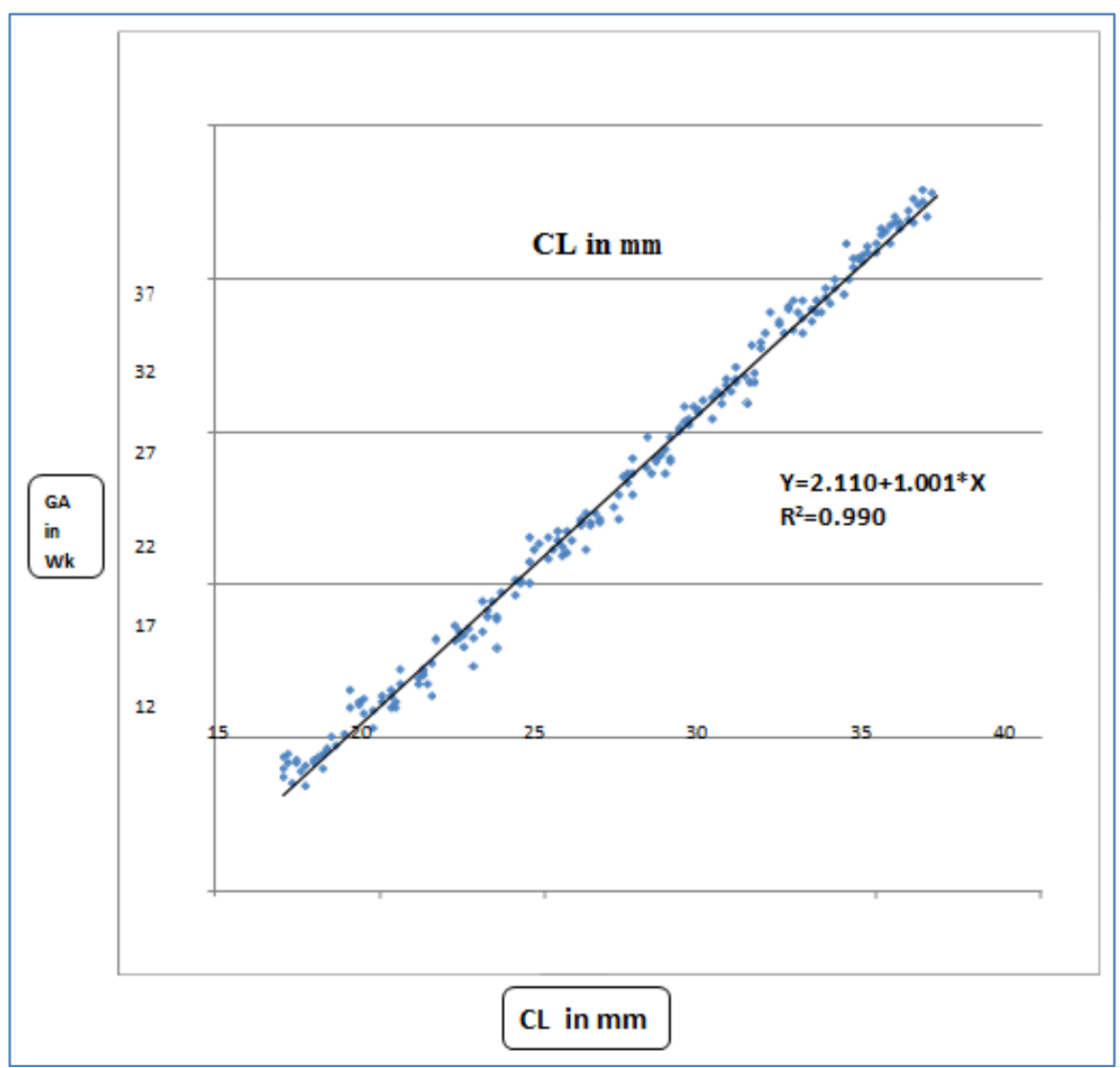

Fig-4: Relationships between clavicular length $(\mathrm{mm})$ and gestational age (weeks)

\section{Indentations and equations}

Regression equation for determination of gestational age using clavicular length is found to be $\mathrm{Y}=2.110+1.001^{*} \mathrm{X}$, where $\mathrm{Y}=$ Fetal gestational age in weeks, $2.11=\mathrm{Y}$ intercept, $1.001=$ slope and $\mathrm{X}=$ fetal clavicular length.

\section{DISCUSSION}

The determination of gestational age is important in obstetric for management of pregnancy and evaluation of fetal development. Higher perinatal mortality has been reported in patients whose expected date of delivery is not known. An error in the GA estimation can result in prematurity and post maturity. Extremes of fetal growth contribute disproportionately to overall perinatal and infant morbidity and mortality. Accurate gestational dating is of paramount importance and the cornerstone of management of pregnancies. Among the various clinical criteria, Last Menstrual Period (LMP) preceded by normal cycle is known to best correlate with the gestational age but it is not reliable when a woman is not sure about her last menstrual period. Ultrasonography is routinely used for dating of pregnancy. For dating of pregnancies CRL is the best parameter. The other biometric parameters used for gestational age assessment are $\mathrm{BPD}, \mathrm{HC}, \mathrm{AC}$ and 
FL. However each of these parameters has their own limitations. Clavicular length is another new and unique parameter, well established as a reliable parameter for estimating the duration of gestation and it is consistently superior in predicting GA in both singeton and twin pregnancy. The fetal clavicle is a consistently identifiable anatomic structure and landmark that has previously been proven to provide a reproducible plane for measurement using ultrasonography. Measurement of the clavicle is of special interest since it permits not only the estimation of gestational age, but also the detection of severe congenital anomalies such as Cleidocranial dysplasia, Holt-Oramsyndrome, MelnickNeedles syndrome and others [19-26]. Measurement of the clavicle by ultrasonography is easily obtainable. We compared the intercept and regression coefficient (slope) between previous and present study as illustrated in table 2. In present study done on 200 pregnant mothers we got a linear regression equation $\mathrm{Y}=2.110+1.001^{*} \mathrm{X}$ and pearson's correlation coefficient of 0.995 as compared to Shaul Yarkoni et al. done on 85 singleton fetus with a linear regression equation of $\mathrm{Y}=3.717+0.827 * \mathrm{X}$ and $\mathrm{R} 2$ of 0.807 . Our study showed comparatively stronger correlation between gestational age and clavicular length in comparison to both the studies of Shaul Yarkoni et al. [26], Fazil Avei et al. [27] and Sherer DM et al. [28] done previously. In future an average gestational can be computed by taking all biometric indices into account including clavicular length.

\section{ACKNOWLEDGEMENTS}

The authors hereby acknowledges Dr. Sumanta Kumar Mandal (Professor), Dr. Rikta Mallik (Associate Professor)., Dr. Bindu Bikash Srimani (RMO), Dr. Runu Dhar (RMO), for their extensive support, Dr. Dipankar Dey, Dr. Dipta Mandal, Dr. Nitish Kr Layek, Dr. Salma Nasrin, Dr. SK. Ajimmuddin and Dhananjay Pramanik and last but not the least the pregnant mothers themselves who were all extremely pivotal and cooperative throughout the study period.

\section{REFERENCES}

1. Mahendru AA, Wilheim-Benartzi CS, Wilkinson IB, Mc Eniery CM, Johnson S, Lees C. Gestational length assignment based on last menstrual period,first trimester crown-rump length,ovulation and implantation timing. Arch Gynecol Obstet. 2016; 294(4):867-76.

2. Kalish R B, Chervenak FA. Sonographic determination of gestational age. Ultrasound Rev Obstet Gynecol. 2005; 5:254-8.

3. Nguyen TL, Engholm G, Moller H. Evaluation of ultrasound-estimated date of delivery in 17450 spontaneous singleton births:do we need modify Naegele's rule?.Obstetrics and Gynecology. 1999;14(1):23-8.

4. Degani S. Fetal biometry: clinical, pathological and technical considerations. Obstet Gynecol Surv.
$2001 ; 56: 159-67$

5. Hohler CW. Ultrasound estimation of gestational age. Clin Obstet Gynecol. 1984;27(2):314-26.

6. Lerner JP. Fetal growth and wellbeing. Obstet Gynecol Clin North Am. 2004; 31:159-76.

7. Filly RA, Golbus MS, Carey JC, Hall JG. Shortlimbed dwarfism: ultrasonographic diagnosis by mensuration of fetal femoral length. Radiology1981; 138(3): 653-6.

8. Hadlock FP, Deter RL, Harrist RB, Park SK. Fetal abdominal circumference as a predictor of menstrual age.AJR Am J Roentgenol 1982;139(2):367-70.

9. Hadlock FP, Deter RL, Harrist RB, Park SK. Fetal biparietal diameter: a critical re- evaluation of the relation to menstrual age by means of realtime ultrasound. Ultrasound Med. 1982;1(3):97-104.

10. Hadlock FP, Deter RL, Harrist RB, Park SK. Fetal head circumference: relation to menstrual age. AJR Am J Roentgenol. 1982;138(4):649-53.

11. Russel L, Deter RL, Ronald B, Harrist RB, Frank P, Hadlock FP, Robert J, Carpenter RJ. Fetal head and abdominal circumferences: II. A critical reevaluation of the relationship to menstrual age. J Clin Ultrasound 1982;10(8):365-72.

12. Hadlock FP, Harrist RB, Deter RL, Park SK. Fetal femur length as a predictor of menstrual age: sonographically measured. AJR Am J Roentgenol. 1982;138(5):875-8.

13. Gorea RK, Mohan P, Garg A, Pathak N. Fetal age determination from length of femur and humerus by ultrasonography.Medico-legal Update. 2009;9(1):23-6.

14. Hadlock FP, Deter RL, Harrist RB, Park SK. The use of ultrasound to determine fetal age- a review.Med Ultrasound1983; 7: 95-03.

15. Campbell S, Wilkin D. Ultrasonic measurement of fetal abdomen circumference in the estimation of fetal weight. Br J Obstet Gynaecol. 1975; 82(9): 689-97.

16. Jeanty P, Rodesch F, Delbeke D, Dumont JE. Estimation of gestational age from measurements of fetal long bones. J Ultrasound Med.1984; 3(2):75-9.

17. Holt M, Oram S. Familial heart disease with skeletal malformations. Br HeartJ. 1960; 22:23642.

18. Forland M. Cleidocranial dysostosis. A review of the syndrome and report of a sporadic case, with hereditary transmission. Am JMed. 1962; 33:792-9.

19. Goltz RW, Peterson WC, Gorlin RJ, Ravits HG. Focal dermal hypoplasia. Arch Dermatol1962; 86:708-17.

20. Melnick JC, Needles CF. An undiagnosed bone dysplasia. A 2 family study of 4 generations and 3 generations. Am J Roentgenol Radium TherNucl Med.1966;97(1):39-48.

21. DeBusk FL. The Hutchinson-Gilford progeria syndrome. Report of 4 cases and review of the literature. J Pediatr. 1972; 80(4):697-24. 
22. Elmore SM. Pycnodysostosis: A review. J Bone Joint Surg. 1967; 49:153-62.

23. Cavendish ME. Congenital elevation of scapula. JBone jointSurg Br. 1972; 54:395-08.

24. Beals RK. Auriculo-osteodysplasia, A syndrome of multiple osseous dysplasia, ear anomaly and short stature. J Bone Joint Surg Am. 1967; 49(8):1541-50.

25. Ogata $S$, Uhthoff HK. The early development and ossification of the human clavicle-an embryologic study. ActaOrthop Scand. 1990; 61(4):330-34.

26. Yarkoni S, Schmidt W, Jeanty P, Reece EA,
Hobbins JC. Clavicular Measurement: A new biometric parameter for fetal evaluation. J Ultrasound Med. 1985; 4(9):467-70.

27. Avci F, Serin S, Bakacak M, Ercan O, Köstü B, Arikan DC. The correlation between gestational age and the length of the clavicle.Perinatal Journal. 2014;22(3):42.

28. Sherer DM, Sokolovski M, Dalloul M, Khourycollado F, Osho JA, Lamarque MD, Abulafia O Fetal clavicle length throught gestation: A nomogram. Ultrasound Obstet Gynecol. 2006; 27:306-10. 